\title{
Determination of Infant and Child Mortality in Kenya Using Cox-Proportional Hazard Model
}

\author{
Daniel Mwangi Muriithi ${ }^{1}$, Dennis K. Muriithi ${ }^{2}$ \\ ${ }^{1}$ School of Biological and Physical Sciences, Moi University, Eldoret, Kenya \\ ${ }^{2}$ Faculty of Business, Chuka University, Chuka, Kenya
}

Email address:

mwangidii@gmail.com (Daniel M. M.), kamuriithi2011@gmail.com (Dennis K. M.)

\section{To cite this article:}

Daniel Mwangi Muriithi, Dennis K. Muriithi. Determination of Infant and Child Mortality in Kenya Using Cox-Proportional Hazard Model. American Journal of Theoretical and Applied Statistics. Vol. 4, No. 5, 2015, pp. 404-413.doi: 10.11648/j.ajtas.20150405.21

\begin{abstract}
One of the Millennium Development Goals is the reduction of infant and child mortality by two-thirds by year 2015. To achieve this goal, efforts need be concentrated at identifying cost-effective strategies as many international agencies have advocated for more resources to be directed to health sector. One way of doing this is to identify the important factors that affect infant and child mortality. This study is necessary because, Infant and child mortality is one of the most important sensitive indicators of the social economic and health status of a community. This is because more than any other age group of a population, infants and children survival depends on the socioeconomic condition of their environment. This study addresses factors affecting infant and child mortality in Kenya. The main objective of the paper is to determine the effect of socioeconomic and demographic variables on infant and child mortality. Childhood mortality from the, KDHS 2008-09 data, was analyzed in two age periods: mortality from birth to the age of 12 months, referred to as "infant mortality" and mortality from the age of 12 months to the age of 60 months, referred to as "child mortality". Data from Kenya Demographic and Health Survey (KDHS 2008-09) was collected by use of questionnaires, after carrying out a two-stage cluster sampling design. The Cox regression survival analysis was used to compute relative risk of the socioeconomic and demographic variables, on infant and child mortality. The study revealed that the socioeconomic and demographic factors affect both infant and child mortality. The relative risks were higher for infant's mortality as compared to child's mortality. The place of birth has the greatest impact on infant mortality. The study recommends policy makers and programme managers in the child health sector to formulate appropriate strategies to improve the situation, of children less than five years in Kenya, by creating awareness on these factors and improving on them.
\end{abstract}

Keywords: Infant Mortality, Child mortality, Wealth Index, Cox-Proportional Hazard Model

\section{Introduction}

Background of Study: Infant and child mortality is one of the most important sensitive indicators of the social economic and health status of a community. This is because more than any other age group of a population, infants and children survival depends on the socioeconomic condition of their environment (Madise et al 1999). It is one of the components of United Nations human development index (UN, 2007). Hence its description is very vital for evaluation and planning of the public health strategies (Park, 2005). One of the most important items in the Millennium Development Goals (MDG) is to reduce infant and child mortality by twothird by 2015 (UNICEF, 2006). In Kenya approximately eight out of each 100 live births die before their first birthday, representing huge wastage of potential manpower. (CBS, 2004). To achieve the MDG requires reduction in the Kenyan Infant mortality rate, to about 22.0 per 1000 live births by 2015. The level of IMR per 1000 live births for Kenya had shown a fluctuating trend in the last 40 years. The trend has been 119 in 1969,88 in 1979 and further declined to 66 per 1000 in 1989 (CBS, 2004) although there was a sudden substantial increase in the year 1999 at 77.3, from 1989 (CBS, 2004) in the year 2009 a decrease to 52.29 was noted from 1999. (CBS, 2011). Researchers have attributed the increase in IMR in 1999 to HIV/AIDS epidemic (UN, 2007). In Kenya, existing studies on child health have focused on medical causes of infant and child mortality (McElroy et al, 2001) and factors associated with under -five mortality (Hill et al, 2001 and Mutunga, 2004). In India, association 
between infant mortality rate and socioeconomic and demographic factors (Arvind P. et al, 1998 and Tulasidhar 1993) was reported. Factors associated with preterm delivery in rural developing countries include low pre- pregnancy weight of the mother, very young maternal age and low maternal socio-economic status and education (Kramer et al, $1987)$. Low birth weight $(<2500 \mathrm{~g})$ is a risk associated with a third of all infant deaths in developing world (two-to-three forced likelihood of death in infancy) (Lovel, 1989). Also in a prospective study (Jansen et al, 1984) carried out in Kenya, Machakos, low birth weight carried a higher risk of death. Mortality in LBW infants was $13 \%$ as compared to $2 \%$ in normal birth weights infants.

Infant and child mortality has been an international social problem for a very long time. In the developed countries, the governments have succeeded in decreasing this phenomenon to remarkable levels through implementing health policies which improves children health care and hence increasing survival rate of the infants and children. In the developing countries, such as Kenya, though the mortality rates are decreasing, they are still high. In Kenya for instance where this study was done the infant mortality rate stands at 52.29 deaths per 1000 infants. (KNBS, 2011). This situation prompted us to delve into issue of infant and child mortality by analyzing the socio-economic and demographic determinants which affect the infant mortality and child mortality to establish whether there exists a relationship between them.

This study aimed at determining the impact of socioeconomic and demographic variables on infant and child mortality by applying cox proportional hazard regression analysis to compute the relative risks on the specified factors. The study was guided by the following specific objectives;

i. To investigate the effect of socioeconomic variable, Education, Occupation and Wealth index of the mother on infant and child mortality using cox proportional hazard regression analysis.

ii. To investigate the effect of Demographic variable; Province of residence, Age of the mother, Gender of the newborn, Place of residence, Birth order, Size of the newborn, Source of drinking water Place of delivery of infant and child, type of toilet used by the family members on infant and child mortality using cox proportional hazard regression analysis.

\section{Literature Review}

Several studies have been done that focused on the determinants of infant and child mortality. Regarding the association between socioeconomic status with infant and child mortality Caldwell (1979) reported on the effects of mother's education on reducing child mortality. He put up a theory that mother's education works through changing feeding and care practices, leading to better health seeking behavior and by changing the traditional familial relationships. In supporting Caldwell's explanation, (Hobcraft, 1993) explained that education can contribute to child survival by making women more likely to marry and enter motherhood later and have fewer children, utilize prenatal care and immunize their children. The result also, however, showed mysterious conclusion that effect of maternal education on child survival is weaker in sub-Sahara Africa (Devlieger, 2005). Evidence from studies that used data of census and demographic surveillance systems (Bhuiyat, 1991) showed the same mortality differential by maternal education. The only identified counterintuitive result on this association was brought by Adetunji (1995) who had examined the 1986-1987 Ondo state DHS using birth history data from 2635 women aged 15-49. The study showed that infant mortality is higher in those born to mothers with secondary education compared to uneducated mothers. He suggested that the lower maternal age at birth and less duration of breastfeeding which were associated with this group of women could be responsible for this finding. However a Tanzania study (Mturi and Curtis 1995), had shown lack of infant and child mortality differentials by such socioeconomic factors as, maternal education partner's education, urban /rural residence, and presence of radio in household. But demographic factors such as short birth interval (less than 2 years) teenage pregnancies $(<20$ years) and previous child death were all significantly associated with increased infant and child mortality.

In Kenya (Hill et al, 2001) reported an inverse relationship between mother's educational level and economic status (wealth index) and child mortality. While for the relationship between urban/rural residence and child mortality, urban areas showed higher mortality risks than rural, but when adjusted for HIV prevalence, child mortality was lower in urban areas. Adjusting for a number of socioeconomic factors (Mutunga, 2004) found that child survival was found better for those who were of birth order 2-3, birth interval more than 2 years, not outcomes of multiple births, living in wealthier households, had access to drinking water and better sanitation facilities and users of low polluting fuels as their main source of cooking. Maternal age, maternal education and gender of the child had no significant association with child mortality. Other studies on determinants of infant and child mortality had supported the significant effect of some biological and demographic predictors of the phenomenon. (Hobcraft et al 1985; Forste, 1994; Hessol et al, 2005; Troe, 2006; Gyimah, 2002).

Zerai (1996) examined socio-economic and demographic variables in a multi-level framework to determine conditions influencing infant survival in Zimbabwe. He employed Cox regression analysis to the 1988 Zimbabwe DHS data to study socioeconomic determinants of infant mortality. The unique finding was that women's average educational level in their community exerts a greater influence on infant survival than the mother's educational level. This result supports assertions that child survival is strongly impacted by mass education (Cleland and Van Ginneken, 1988). Bicego (1990) applied a three-step procedure using proportional hazards regression to estimates trends and determinants of childhood mortality in Haiti. He used the data from the 1987 mortality, morbidity 
and services utilization survey (MMUS) in Haiti. Maternal education and low age at birth were found to have marked effects on neonatal survivorship but little effect thereafter.

Manda (1999) used data from 1992 DHS in Malawi to study the relationship between infant and child mortality and birth interval. Maternal age at birth and birth order with and without controlling for other relevant explanatory variables. He also investigated the direct and indirect (through its relationship with birth intervals) effects of breastfeeding on childhood mortality. The study employed proportional hazards models. The results show that birth interval and maternal age effects are largely limited to the period of infancy. Hisham et al (2008) examined socioeconomic determinants of infant mortality in Kenya. They employed the logistic regression model, in testing the magnitude of the significance of each selected variable on the $2003 \mathrm{KDHS}$ data to study socioeconomic determinants of infant mortality. The factors were then rank -ordered according to their overall P-value. Their study did not show the differential impact of the independent variables on infant and child mortality. The current research seeks to fill this gap in the existing literature on infant and childhood mortality by analyzing how child and infant mortality are differently impacted by the aforementioned variables particularly in Kenya. Cox proportional hazards model was used to analyze several independent variables on infant and child mortality. The data from 2008-2009 Kenya Demographic and Health Survey will be used. Joshua et al, (2009) carried down a related study in Zimbabwe and reported association on socioeconomic and demographic factors on infant and child mortality.

\section{Methodology}

\subsection{Introduction}

The study is an analytical cross-sectional study through secondary data of the 2008-2009 Kenya Demographic Health Survey (KDHS). The 2008-2009 KDHS was a nationally representative sample survey of 10,000 households using a two-stage sampling design. In the first stage, 400 clusters133 urban and 267 rural, were selected from the master frame. The second stage of selection involved the systematic sampling of households from a list of households. A total of 9,936 households were selected in the sample of which 9,268 were occupied at the time of fieldwork and thus eligible for interviews. Out of the 9,268 households, 9057 women were successfully interviewed by use of a questionnaire, yielding a response rate of 98 percent. The shortfall in the number of households was largely due to households whose members were absent for an extended period during data collection. The eligible respondents were all women aged 15-49. From those interviewed, 8767 women were found to be eligible and 8,444 were interviewed, giving a response rate of $96 \%$. Interviews with men, covered 3,465 of the eligible 3910 men aged (15-54) yielding a response rate of $89 \%$ the response rates are generally higher in rural than in urban areas. The study population for this analysis included infants born between exactly one and five years preceding the 2008-2009 KDHS: who were the outcomes of singleton deliveries and who either survived the infancy period or not.

\subsection{Model Specification}

Childhood mortality was analyzed in two age periods; mortality from birth to the age of 12 months which will be referred to as "Infant Mortality" and mortality from the age of 12 months to the age of 60 months; which will be referred as "Child Mortality". In both cases the dependant variable is risk of death occurring in an age interval, in a period such as from birth to age one in a calendar year. The independent variables:

- Socioeconomic variables: (Maternal Education, Wealth Index, maternal occupation )

- Demographic variables: (child's birth order, maternal age, child's sex, birth size, place of delivery, source of water, type of toilet facility, type of place of residence rural or urban and province of residence).

The dependent Variable:

- Infant Mortality: Probability of dying between birth and the first birthday

- Child Mortality: the probability of dying between the exact age one and the fifth birthday.

\subsection{Source of Data}

The study used secondary data of 2008-09 Kenya Demographic Health Survey dataset for children. The 200809 KDHS dataset was downloaded from Macro International Inc Website after obtaining permission to do so, from Macro International, USA. The children data was opened by the software, Statistical Package for Social Scientists (SPSS, version 20.0), because it was the only available program for opening the data. The total number of live births between years 2004-2008 was 5878. The number of Under-5 deaths during the same period was 277. Of these deaths, 234 occurred during Infancy (0-12 months) and 43 during childhood (13-60 months).

\subsection{Statistical Model}

The data obtained from Kenya Demographic and Health Survey 2009 (KDHS) was analyzed using the COXREG Survival analysis command, in Statistical Package for Social Science (SPSS 20.0) program. The program was used to compute the Cox proportional hazard ratios for the determinants of infant and child mortality. The proportional hazard model, which stems from the work of Cox (1972), assumes that for an individual with a vector of Covariates in $x_{i}$, the hazard rate (death rate) at time $t_{i}$ is given by:

$$
h_{i}\left(t_{i} ; x_{i}\right)=h_{o}\left(t_{i}\right) \exp \left(\beta^{i} x_{i}\right)
$$

Where $\mathrm{h} i\left(\mathrm{t} i \mathrm{x}_{\mathrm{i}}\right.$ ) is the hazard function for the comparison group at time ti with $x i=1$.

$\beta \mathrm{i}$ is a vector of unknown coefficients of covariate effects $\mathrm{xi}$ is a known vector of regressor variables associated with 
the individual

$\mathrm{h} 0$ (ti) is the baseline hazard function for an individual with $\mathrm{xi}=0$ at time ti

The relative risk is given by:

$$
\frac{h_{i}\left(t_{i} ; x_{i}\right)}{h_{o}\left(t_{i}\right)}=e^{\beta^{i} x_{i}}
$$

if:

$e^{\beta x}<1$ risk of dying is less in the comparison group

$e^{\beta x}>1$ risk of dying is greater in the comparison group

$e_{i i}^{\beta x}=1$ risk of dying is equal in the two groups

Assumptions of the model

1) First and foremost is the issue of non-informative censoring. To satisfy this assumption, the design of the underlying study must ensure that the mechanisms giving rise to censoring of individual subjects are not related to the probability of an event occurring. For example, in clinical studies, care must be taken that continuation of follow-up not depend on a participants medical condition.
2) The second key assumption in the Cox model is that of proportional hazards. In a regression typesetting this means that the survival curves for two strata (determined by the particular choices of values for the $x$-variables) must have hazard functions that are proportional over time (i.e. constant relative hazard). We have seen how this can be evaluated graphically using "log-log" plots in the two-sample comparison case. In that situation, and also for the Cox model, there are tests that can be applied to test proportionality.

\section{Model Results and Discussion}

\subsection{Effect of Socioeconomic Variables on Infant and Child Mortality}

The study sought to establish the effect of socioeconomic variables on infant and child mortality and the results are provided in Table 1(a) and Table 1(b).

Table 1(a). Impact of socioeconomic variables on infant mortality, Hazard model estimates of relative risk (RR).

\begin{tabular}{|c|c|c|c|c|c|c|c|}
\hline & \multirow{2}{*}{ B } & \multirow{2}{*}{ SE } & \multirow{2}{*}{ DF } & \multirow{2}{*}{ Sig } & \multirow{2}{*}{$\operatorname{EXP}(\beta)$} & \multicolumn{2}{|l|}{$95 \% \mathrm{Cl}$} \\
\hline & & & & & & LOWER & UPPER \\
\hline \multicolumn{8}{|l|}{ Education } \\
\hline Secondary + & & & 2 & .313 & 1 & & \\
\hline No Education & .108 & .372 & 1 & .387 & 1.114 & .350 & 1.502 \\
\hline Primary & .071 & .218 & 1 & .621 & 1.074 & .726 & 1.708 \\
\hline \multicolumn{8}{|l|}{ Wealth } \\
\hline Richest & & & 4 & .487 & 1 & 1 & \\
\hline Poorer & .275 & .340 & 1 & .211 & 1.317 & .366 & 1.942 \\
\hline Middle & -.092 & .310 & 1 & .765 & .912 & .497 & 1.672 \\
\hline Richer & -.341 & .285 & 1 & .231 & .711 & .407 & 1.242 \\
\hline \multicolumn{8}{|l|}{ Occupation } \\
\hline Unskilled & & & 7 & .006 & 1 & 1 & \\
\hline Not Working & -.137 & .527 & 1 & .794 & .872 & .310 & 2.449 \\
\hline Teach /Manager & -.573 & .539 & 1 & .816 & .564 & .394 & 3.260 \\
\hline Clerical & .729 & .560 & 1 & .626 & 2.072 & .438 & 3.941 \\
\hline Agri. S. employ & .733 & .538 & 1 & .173 & 1.342 & .726 & 5.974 \\
\hline Agric Employee & -.104 & .563 & 1 & .853 & .901 & .299 & 2.716 \\
\hline Domestic & .441 & .603 & 1 & .464 & 1.555 & .477 & 5.070 \\
\hline
\end{tabular}

From Table 1(a), education of the mother shows a decrease in infant mortality associated with an increase in maternal schooling. Those infants born to mothers with primary education have a higher risk (1.074) than those with secondary + education. Those infants born to mothers without education have higher risk of dying (1.114) than those born to mothers with secondary + , education. This is due to the fact that mothers with high education are more enlightened on better methods of prenatal and antenatal care (Hill et al 2001).On the wealth factors, it is shown that infants born to poor mothers are at a higher risk of dying (1.685 times) than those who are richest. This is due to lack of affordability of good nutrition and medical attention for both mother and the infant. Those infants born to richer mothers experience the lowest risk (0.728). Their mortality is lower than, even, for the richest. This is because these mothers can afford good nutrition and have time to be with their babies, unlike the richest who are ever busy, without time for their babies. Mturi et al, (1995). Occupation of the mother also affects the infant mortality. Infants born to mothers who work as sales agents have the greatest risk (2.072) as compared to other occupation. Those working as teacher or manager have the lowest (0.564).This is due to availability of the mother when the infant is in any need. These parents have knowledge on good nutrition and can afford good medication for themselves and the infant. Hisham et al, (2008). 
Table 1(b). Impact of socioeconomic variables on child mortality, Hazard model estimates of relative risk (RR).

\begin{tabular}{|c|c|c|c|c|c|c|c|}
\hline & \multirow{2}{*}{ B } & \multirow{2}{*}{ SE } & \multirow{2}{*}{ DF } & \multirow{2}{*}{ SIG. } & \multirow{2}{*}{$\operatorname{EXP}(\beta)$} & \multicolumn{2}{|l|}{$95 \% \mathrm{CI}$} \\
\hline & & & & & & Lower & Upper \\
\hline \multicolumn{8}{|l|}{ Education } \\
\hline Secondary + & & & 2 & .684 & 1 & & \\
\hline No Education & .068 & .961 & 1 & .756 & 1.070 & .113 & 2.881 \\
\hline Primary & .057 & .557 & 1 & .659 & 1.059 & .407 & 2.944 \\
\hline \multicolumn{8}{|l|}{ Occupation } \\
\hline Unskilled & & & 7 & .880 & 1 & & \\
\hline Not Working & -.036 & .833 & 1 & .285 & .965 & .080 & 2.099 \\
\hline Teach /Manager & -1.398 & .909 & 1 & .124 & .247 & .042 & 1.264 \\
\hline Clerical & -.494 & 2391.31 & 1 & .996 & .610 & .178 & 1.379 \\
\hline Sales & .021 & .947 & 1 & .265 & 1.021 & .054 & 2.226 \\
\hline Agri. S. Employed & -1.351 & .941 & 1 & .087 & .259 & .032 & 1.264 \\
\hline Agri-Employee & -.944 & .900 & 1 & .294 & .389 & .067 & 2.270 \\
\hline Domestic & -1.082 & 1.308 & 1 & .408 & .339 & .026 & 4.403 \\
\hline \multicolumn{8}{|l|}{ Wealth } \\
\hline Richest & & & 4 & .581 & 1 & & \\
\hline Poorest & .519 & .891 & 1 & .831 & 1.680 & .144 & 4.44 \\
\hline Poorer & .278 & .829 & 1 & .530 & 1.321 & .331 & 8.561 \\
\hline Middle & .067 & .821 & 1 & .735 & 1.069 & .264 & 6.607 \\
\hline Richer & -.099 & .789 & 1 & .899 & .905 & .193 & 4.250 \\
\hline
\end{tabular}

From Table 1(b), the effect of education of the mother shows a decrease in child mortality associated with an increase in maternal schooling. Those children born to mothers with no education have a higher risk (1.070) of dying than those with secondary and above education . Those children born to mothers with secondary and higher, experience lower risk of dying than those born to mothers with primary education (1.059). This is due to the fact that mothers with high education are more enlightened on better methods of rearing children Caldwell (1979); Hobcraft (1993) reported similar findings on the effect of mother's education. On the wealth factors it is shown that children born to poorest mothers are at the highest risk of dying (1.680 times) than those who are richest. This is due to lack of affordability of good nutrition and medication for both mother and the child. Those children born to richer mothers experience the lowest mortality. Their mortality is lower than, even, for the richest Hobcraft (1993). This is because these mothers can afford good nutrition. More so, these are the middle class mothers and their availability for their children is assured. Children born to mothers who work as sales agents have the greatest risk (1.021) as compared to unskilled occupation. Those working in teachers or managers have the lowest (0.247) compared to unskilled Hisham et al, (2008).

\subsection{Effect of Demographic Variables on Infant and Child Mortality}

The study sought to establish the effect of demographic variables on infant and child mortality and the results are provided in Table 2(a) and Table 2(b).

Table 2(a). Impact of Demographic variables on infant mortality, Hazard model estimates of relative risk (RR).

\begin{tabular}{|c|c|c|c|c|c|c|c|}
\hline & \multirow{2}{*}{$\boldsymbol{\beta}$} & \multirow{2}{*}{ SE } & \multirow{2}{*}{ DF } & \multirow{2}{*}{ SIG. } & \multirow{2}{*}{$\operatorname{EXP}(\beta)$} & \multicolumn{2}{|l|}{$95.0 \%$ CI } \\
\hline & & & & & & LOWER & UPPER \\
\hline \multicolumn{8}{|l|}{ Province } \\
\hline N. Eastern & & & 7 & .240 & 1 & & \\
\hline Nairobi & -.263 & .570 & 1 & .645 & .769 & .251 & 2.351 \\
\hline Central & -.031 & .579 & 1 & .971 & .732 & .329 & 3.176 \\
\hline Coast & -.014 & .467 & 1 & .920 & .986 & .420 & 2.618 \\
\hline Eastern & -1.018 & .520 & 1 & .050 & .361 & .130 & 1.001 \\
\hline Nyanza & .047 & .510 & 1 & .521 & 1.048 & .265 & 1.960 \\
\hline R. Valley & -.278 & .487 & 1 & .314 & .757 & .236 & 1.591 \\
\hline Western & .021 & .551 & 1 & .864 & 1.021 & .374 & 3.234 \\
\hline \multicolumn{8}{|l|}{ Age } \\
\hline $35-49$ & & & 2 & .099 & 1 & & \\
\hline $15-24$ & .088 & .261 & 1 & .086 & 1.092 & .384 & 1.066 \\
\hline $25-34$ & -.437 & .205 & 1 & .033 & .646 & .432 & .965 \\
\hline \multicolumn{8}{|l|}{ Residence } \\
\hline Rural & & & 1 & .102 & 1 & & \\
\hline Urban & -.265 & .254 & 1 & .297 & .767 & .467 & 1.262 \\
\hline \multicolumn{8}{|l|}{ Gender } \\
\hline Female & & & 1 & & 1 & & \\
\hline Male & .217 & .133 & 1 & .102 & 1.243 & .927 & 1.613 \\
\hline
\end{tabular}




\begin{tabular}{|c|c|c|c|c|c|c|c|}
\hline & \multirow{2}{*}{$\beta$} & \multirow{2}{*}{ SE } & \multirow{2}{*}{ DF } & \multirow{2}{*}{ SIG. } & \multirow{2}{*}{$\operatorname{EXP}(\beta)$} & \multicolumn{2}{|l|}{$95.0 \% \mathrm{CI}$} \\
\hline & & & & & & LOWER & UPPER \\
\hline \multicolumn{8}{|l|}{ Place of delivery } \\
\hline Private Medical & & & 7 & .001 & 1 & & \\
\hline Respondents Home & .351 & .438 & 1 & .000 & 1.421 & .060 & 1.635 \\
\hline Other Home & .344 & .487 & 1 & .000 & 1.411 & .069 & 1.863 \\
\hline Enrute To Providers & .358 & 1.093 & 1 & .025 & 1.430 & .010 & 1.703 \\
\hline Gov Hosp. & .075 & .450 & 1 & .000 & 1.078 & .074 & .429 \\
\hline Gov. Dispensary & .081 & .576 & 1 & .003 & 1.084 & .060 & .570 \\
\hline Mission Clinic & -1.655 & .529 & 1 & .002 & .191 & .068 & .539 \\
\hline Nursing Maternity & -2.273 & 1.098 & 1 & .038 & .103 & .012 & .886 \\
\hline \multicolumn{8}{|l|}{ Birth order } \\
\hline $6+$ & & & 2 & .497 & 1 & & \\
\hline 1 & .275 & .304 & 1 & .365 & 1.317 & .726 & 2.389 \\
\hline $2-5$ & -.317 & .221 & 1 & .237 & .728 & .842 & 2.002 \\
\hline \multicolumn{8}{|l|}{ Birth size } \\
\hline Smaller than average & & & 3 & .760 & 1 & & \\
\hline Very large & -.318 & .343 & 1 & .354 & .728 & .371 & 1.425 \\
\hline Large than average & -.168 & .196 & 1 & .388 & .845 & .576 & 1.239 \\
\hline Average & -.119 & .189 & 1 & .527 & .887 & .613 & 1.285 \\
\hline \multicolumn{8}{|l|}{ Source of drinking water } \\
\hline Tank truck & & & 10 & .159 & 1 & & \\
\hline Piped dwelling & -.689 & .571 & 1 & .227 & .502 & .164 & 1.537 \\
\hline Piped to yard plot & -.691 & .417 & 1 & .720 & .501 & .512 & 2.632 \\
\hline Public tap & -.054 & .412 & 1 & .895 & .947 & .423 & 2.123 \\
\hline Borehole & -.158 & .424 & 1 & .709 & .854 & .372 & 1.959 \\
\hline Protected well & -.729 & .448 & 1 & .103 & .482 & .200 & 1.158 \\
\hline Unprotected well & .229 & .490 & 1 & .245 & 1.257 & .217 & 1.477 \\
\hline Protected spring & -.667 & .469 & 1 & .155 & .513 & .205 & 1.287 \\
\hline Unprotected spring & .036 & .494 & 1 & .238 & 1.037 & .212 & 1.470 \\
\hline River ,lake/dam & .282 & .411 & 1 & .199 & 1.326 & .264 & 1.320 \\
\hline Rain water & -.337 & .638 & 1 & .598 & .714 & .204 & 2.495 \\
\hline \multicolumn{8}{|l|}{ Type of Toilet } \\
\hline Basket toilet & & & 8 & .219 & 1 & & \\
\hline Flush to piped water system & .605 & .767 & 1 & .430 & 1.832 & .408 & 2.236 \\
\hline Flush to septic tank & -.722 & 1.216 & 1 & .553 & .486 & .045 & 1.268 \\
\hline Flash to latrine & -.038 & .991 & 1 & .970 & .963 & .138 & 1.724 \\
\hline Flash to some where else & -9.061 & 129.582 & 1 & .944 & .000 & .000 & 2.320 \\
\hline Flash to I don't know & 1.964 & .922 & 1 & .033 & 7.126 & 1.169 & 9.419 \\
\hline Pit latrine with Slab & -.015 & .684 & 1 & .479 & .985 & .425 & 1.204 \\
\hline Pit latrine without slab & -.059 & .672 & 1 & .243 & .943 & .587 & 2.191 \\
\hline Bush & .981 & .165 & 1 & .151 & 2.667 & .698 & 3.189 \\
\hline
\end{tabular}

In Table 2(a), the infant risk of dying is affected by the province of residence. Infants born to mothers living in Coast, Eastern, Central, Nairobi, Rift valley regions have lower relative risk of death at infancy, $(.986, .361, .732, .769, .757$ respectively) relative to those born to mothers residing in North Eastern region. This may be explained by the fact that, these provinces have more health centers than North Eastern province. Nyanza and Western provinces have higher relative risk of infant death $(1.048,1.021)$ than North Eastern. Similar finding was reported by Hisham et al, (2008), after carrying out Logistic regression on demographic variables on KDHS 2003-04. This result can be explained by the fact that these provinces have higher HIV prevalence than North Eastern (CBS 2004. Those infants born to mothers living in rural areas have a greater risk of dying relative to those in urban areas (0.767). This is due to unavailability of adequate health facilities in rural areas. Moreover the infrastructure is not well developed in rural areas as compared to urban, to facilitate movement of mothers to access better health facilities in urban areas.

In the model, the mortality relative risk for birth order is in the expected direction. Births of order six or higher with short preceding interval have the highest mortality risk, Hisham et al, (2008). Infants with these characteristics are 1.298 times more likely to die in infancy relative to births of order two through five with long preceding interval. These results, considered together, highlight the importance of parity in determining infant survival. Results from the model further show that maternal age of less than 20 years of age increases the risk of infant mortality (1.092) relative to maternal age between 35-49. Also maternal age of 35 and higher has a greater risk as compared to risk of 0.646 for age 25-34. Low (less than 20 years) and high (40-49 years) maternal ages predispose infants to elevated mortality risks during infancy, but the risk is greater to mothers who are below 20 years, because their body systems are not fully developed. So, there arise more complications during delivery process as compared to ages 25-34, Hisham et al, (2008).Place of delivery is another factor, which greatly affects the infant mortality. Infants born in medical hospitals are at lower risk than those born at home or in other places other than medical centers. This is due to lack of medical 
facilities and skills during delivery process. If complications arise during delivery, the infant may end up with a terminal illness and dies later in life, Manda (1999). Those born at home have 1.178 relative risk of dying than those born at a nursing maternity.

Those who are born at private hospitals have a lower risk than the once born in public hospitals, government dispensary, government hospitals $(1.078,1.084)$. Private hospitals have better facilities, health workers and drugs as compared to public hospitals which are prone to inadequacy of drugs, facilities and doctors, Mturi et al., (1995). Those born at home have the greatest risk (1.421) due to lack of medical facilities at home during time of delivery. Infants born with smaller than average size has a greater risk than the average larger than average and very large sizes $(.887, .845$, 728) This is due to the fact that their bodies are weak thus prone to sickness. Infants born with larger than average and very large size have lower risk, because their body is stronger hence can resist infections, Manda (1999). For infants born to mothers in households with access to piped drinking water the risk of dying is reduced (0.502) relative to infants born to mothers in households without access to piped drinking water, tank trunk. Piped water reduces waterborne diseases as compared to spring water. Infants born to mothers in households with access to improved toilet facilities(flush to septic tank) are associated with a lower risk of dying $(0.486)$ in infancy compared to those born to mothers in households without access to such facilities. Proper disposal of human waste reduces chances of contracting communicable diseases. Mturi et al., (1995) reported similar findings. Female infants have a lower risk of dying than the male infants (1.243).

Table 2(b). Impact of Demographic variables on child mortality, Hazard model estimates of relative risk (RR).

\begin{tabular}{|c|c|c|c|c|c|c|c|}
\hline & \multirow{2}{*}{$\boldsymbol{\beta}$} & \multirow{2}{*}{ SE } & \multirow{2}{*}{ DF } & \multirow{2}{*}{ SIG. } & \multirow{2}{*}{$\operatorname{EXP}(\beta)$} & \multicolumn{2}{|l|}{$95 \% \mathrm{CI}$} \\
\hline & & & & & & Lower & Upper \\
\hline \multicolumn{8}{|l|}{ Province } \\
\hline N. Eastern & & & 7 & .798 & 1 & & \\
\hline Nairobi & -.371 & 5.026 & 1 & .985 & .690 & .113 & 1.954 \\
\hline Central & -.534 & 1.628 & 1 & .743 & .586 & .024 & 1.874 \\
\hline Coast & -2.465 & 3.199 & 1 & .440 & .085 & 000 & 4.702 \\
\hline Eastern & .680 & 1.153 & 1 & .555 & 1.974 & .206 & 2.537 \\
\hline Nyanza & 1.376 & 1.464 & 1 & .347 & 3.960 & .225 & 6.396 \\
\hline R. Valley & .450 & 1.307 & 1 & .730 & 1.569 & .121 & 4.564 \\
\hline Western & .382 & 1.561 & 1 & .807 & 1.465 & .069 & 3.121 \\
\hline \multicolumn{8}{|l|}{ Age } \\
\hline $35-39$ & & & 2 & .385 & 1 & & \\
\hline $15-24$ & .064 & .667 & 1 & .533 & 1.066 & .179 & 2.414 \\
\hline $25-34$ & -.713 & .557 & 1 & .201 & .490 & .164 & 1.461 \\
\hline \multicolumn{8}{|l|}{ Gender } \\
\hline Male & & & 1 & 0.700 & 1.131 & & \\
\hline Female & .123 & .753 & 1 & 0.850 & 1 & .605 & 2.116 \\
\hline \multicolumn{8}{|l|}{ Residence } \\
\hline Urban & & & 1 & 0.138 & .327 & & \\
\hline Rural & -1.118 & -.753 & 1 & 0.211 & 1 & .075 & 1.430 \\
\hline \multicolumn{8}{|l|}{ Place of delivery } \\
\hline Private Medical & & & 7 & .001 & 1 & & \\
\hline Respondent Home & -3.649 & .716 & 1 & .000 & .026 & .006 & 0.106 \\
\hline Other Home & -.3 .649 & .843 & 1 & .000 & .026 & .005 & 0.134 \\
\hline Enrute toProviders & -19.149 & 2558.36 & 1 & .994 & .000 & .000 & .000 \\
\hline Government Hosp. & -2.781 & .771 & 1 & .000 & .062 & .014 & .280 \\
\hline Gov. Dispensary & -3.507 & 1.234 & 1 & .005 & .030 & .003 & .342 \\
\hline Mission Clinic & -17.358 & 1096.62 & 1 & .987 & .000 & .000 & .000 \\
\hline Nursing Maternity & -16.623 & 2833.89 & 1 & .995 & .000 & .000 & 0.322 \\
\hline \multicolumn{8}{|l|}{ Birth order } \\
\hline $6+$ & & & 2 & .769 & 1 & & \\
\hline 1 & .033 & .559 & 1 & .598 & 1.034 & .449 & 4.017 \\
\hline $2-5$ & -1.655 & .746 & 1 & .929 & .191 & .247 & 4.615 \\
\hline \multicolumn{8}{|l|}{ Birth size } \\
\hline S. than average & & & 3 & .431 & 1 & & \\
\hline Very large & -.309 & .695 & 1 & .900 & .734 & 235 & 3.575 \\
\hline L. than average & -.148 & .489 & 1 & .153 & .862 & .191 & 1.297 \\
\hline Average & -.128 & .430 & 1 & .766 & .880 & .379 & 2.043 \\
\hline \multicolumn{8}{|l|}{ Source of drinking } \\
\hline water & & & & & & & \\
\hline Tank truck & & & 10 & .853 & 1 & & \\
\hline Piped dwelling & -1.016 & 660.445 & 1 & .986 & .362 & .113 & 4.647 \\
\hline Piped to yard plot & -.819 & 1.788 & 1 & .489 & .441 & .103 & 4.443 \\
\hline Public tap & -.044 & 1.738 & 1 & .605 & .957 & .081 & 4.064 \\
\hline Borehole & .223 & 1.766 & 1 & .900 & 1.250 & .039 & 3.842 \\
\hline
\end{tabular}




\begin{tabular}{|c|c|c|c|c|c|c|c|}
\hline & \multirow{2}{*}{$\boldsymbol{\beta}$} & \multirow{2}{*}{ SE } & \multirow{2}{*}{ DF } & \multirow{2}{*}{ SIG. } & \multirow{2}{*}{$\mathbf{E X P}(\beta)$} & \multicolumn{2}{|l|}{$95 \% \mathrm{CI}$} \\
\hline & & & & & & Lower & Upper \\
\hline Protected well & .524 & 1.716 & 1 & .760 & 1.689 & .058 & 4.239 \\
\hline Unprotected well & .629 & 1.784 & 1 & .725 & 1.875 & .057 & 3.657 \\
\hline Protected spring & -.920 & 1.841 & 1 & .617 & .399 & .011 & 1.424 \\
\hline Unprotected spring & .067 & 1.782 & 1 & .970 & 1.069 & .033 & 3.139 \\
\hline River ,lake/dam & .355 & 1.694 & 1 & .834 & 1.426 & .052 & 3.423 \\
\hline Rain water & 14.655 & 1321.65 & 1 & .991 & .000 & .000 & .000 \\
\hline \multicolumn{8}{|l|}{ Type of Toilet } \\
\hline Basket toilet & & & 7 & .982 & 1 & & \\
\hline Flush to septictank & -.268 & 1589.42 & 1 & .994 & .765 & .021 & 2.356 \\
\hline Flash to latrine & -.013 & 1101.49 & 1 & .990 & .987 & .0375 & 1.574 \\
\hline Flashsomewhere else & -.010 & 2999.34 & 1 & .996 & .990 & .0193 & 2.570 \\
\hline Flash to I don't know & -1.118 & 6624.75 & 1 & .998 & .327 & .0185 & 1.934 \\
\hline Pitlatrine with Slab & -1.090 & 1.756 & 1 & .535 & .336 & .011 & 1.978 \\
\hline Pit latrine without slab & -.543 & 1.717 & 1 & .752 & .581 & .020 & 1.994 \\
\hline Bush & -.158 & 1.704 & 1 & .926 & .854 & .030 & 1.587 \\
\hline
\end{tabular}

From the Table 2(b) the child risk of dying is affected by the province of residence. Children born to mothers living in Nairobi, Central, and coast have lower relative risk compared to N. Eastern $(0.69,0.586$, and 0.085 respectively). Eastern, Nyanza, Rift valley and Western provinces have the highest risks compared to North Eastern (1.974, 3.960, 1.569, and 1.465 respectively). It's important to note that a child being brought up in Nyanza has the greatest risk (3.960) of dying during childhood, Hill et al, 2001. Those children born to mothers living in rural areas have a greater risk of dying relative to those in urban areas (0.327). This is due to unavailability of adequate health facilities in rural areas Hill et al, 2001. Moreover the infrastructure is not well developed in rural areas as compared to urban, to facilitate movement of mothers to access better health facilities in urban areas. Births of order six or higher with short preceding interval have the highest mortality risk. Hobcraft (1993) Children with these characteristics are more likely to die in childhood relative to births of order two through five (.191). Results in the model further show that maternal age of less than 20 years of age increases the risk of child mortality (1.066) relative to maternal age of 35-49. Also maternal age of 35 and higher has a greater risk as compared to age 25-34 (0.490). Low (less than 20 years) and high (40-49 years) maternal ages predispose children to elevated mortality risks during childhood, but the relative risk is greater to children born to mothers who are below 20 years because they have little knowledge on children rearing practices and in most cases leave the children to care takers if they are in school, Hobcraft (1993).

Place of delivery is another factor, which greatly affects the child mortality. Children born in medical hospitals are at lower risk than those born at home or in other places other than medical centers. This is due to lack of early immunization and specialized healthcare when born. If complications arise during delivery and the baby survives infancy, he/she may end up with a terminal illness and dies later in life, Hisham et al, (2008).

Children born with smaller than average size have a greater risk than the average size (.880) this is due to the fact that their bodies are weak thus prone to sickness which might kill later in life. Children born with larger than average size have lower risk (0.862) than the smaller than average size, their body is stronger hence can resist more infections Hisham et al., (2008). For children born to mothers in households with access to piped drinking water the risk of dying is reduced (.362) relative to children born to mothers in households without access to piped drinking water, tank truck. Piped water reduces waterborne diseases as compared to spring water because it is treated, Mturi et al., (1995). Children born to mothers in households with access to improved toilet facilities are associated with a lower risk of dying than those born in households without improved toilet facility in childhood, compared to those born to mothers in households without access to such facilities. Proper disposal of human waste reduces chances of contracting communicable diseases, Mturi et al., (1995). Female children have a lower risk of dying than the male children (1.131). Lower probability of dying in childhood for females compared to males is consistent with many studies all over the world. (Hill et al, 2001) it has been reported that for biological reasons males are more prone to die in first months of life. Moreover, due to the fact that male children are more aggressive and take up risky activities, such as, fighting while still young.

\section{Conclusion and Recommendation}

From the results presented, we conclude that: Education of the mother has an effect on infant and child mortality. Infant and child mortality decrease with increased in maternal education. Occupation of the mother has an effect on infant and child mortality. Some occupation of the mother exposes the infants and children, to risks of mortality and morbidity. Wealth index of the mother has an effect on infant and child mortality. Infants and children born to poor mothers are at a higher risk than those born to rich mothers. Province of residence has an effect on infant and child mortality. As shown, infant and child mortality depends on the province of residence. The age of the mother has an effect on infant and child mortality. Infants and children born to mothers who are below 20 years of age and more than 40 years of age have higher relative risk of dying as compared to those born to mothers between ages 20 and 40 years. Gender of the 
newborn has an effect on infant and child mortality. Male infants and children have a higher relative risk as compared to female infants and children. Place of residence has an effect on infant and child mortality. Infants born to mothers residing in rural areas have higher relative risk of dying than those in urban areas. Place of delivery has an effect on infant and child mortality. Infants and children born in health facilities have lower relative risk of dying than those born at home. Birth order of the newborn has an effect on infant and child mortality. Infants and children of order 1 and order $6+$, have higher relative risk, than infants and children of order 25. Size of the newborn has an effect on infant and child mortality. Infants and children who are born being smaller than average by size, have higher relative risk of dying than those who are average larger than average and very large, by size. Source of drinking water has an effect on infant and child mortality. The relative risks for infant and child mortality, are lower for those born in households accessed with piped water and protected springs. Infant and child mortality is at highest on households who use water from unprotected well. Type of toilet used by the family members has an effect on infant and child mortality. Those households without proper system of disposing off human waste, have high relative risk of infant and child mortality. The study recommends policy makers and programme managers in the child health sector to formulate appropriate strategies to improve the situation, of children less than five years in Kenya, by creating awareness on these factors and improving on them.

\section{Acknowledgement}

I sincerely appreciate my co-author, Dennis K Muriithi for his professional guidance, input and availability in the preparation of this paper.

\section{References}

[1] Adetunji, J, A. (1995) "Infant Mortality and Mother's Education in Ondo State, Nigeria". Social Science and Medicine; 40(2):253-263.

[2] Arvind P. Minja K. Norman Y. Luther, Damoda S, and Jagdish C. (1998). Infant and Child Mortality in India.

[3] Bhuiyat, A. and K. Streatfield. (1991) "Mothers' and Survival of Female Children in a Rural Area of Bangladesh". Population Studies; 45:253-264.

[4] Bicego, G. (1990).Trends, age patterns and determinants of childhood mortality in Haiti. [PhD dissertation]. Baltimore: The Johns Hopkins University.

[5] Caldwell, J. C. (1979), Education as a factor in Mortality Decline: An Examination of Nigeria Data. Population Studies; 33 (3): 395-413.

[6] Central Bureau of Statistics (CBS) [Kenya], Ministry of Health (MOH), and ORC Macro, (2004) Kenya Demographic and Health Survey 2008 .Calverton, Maryland: CBS, MOH, and ORC Macro.
[7] Cleland, J. G. and Van Ginneken, J. K. (1988). Maternal education and child survival in developing countries: The search for pathways of influence. Social science and Medicine 27 (12).

[8] Cox, D. R. (1972). Regression models and life tables. Journal of the Royal Statistical Society Series B (methodological) 34 (2): 187-220.

[9] Devlieger, H., G. Mortens and A, Bekaert. (2005). "Social inequalities in prenatal and infant mortality in the northern region of Belgium (the Flanders)" European Journal of Public Health; 15(1): 15-19.

[10] Forste, R. (1994). "The Effects of Breastfeeding and Birth Spacing on Infant and Child Mortality in Bolivia”. Population Studies; 48: 497-511.

[11] Hisham, E. M. and Clifford, O. (2008). socioeconomic Determinants of Infant Mortality in Kenya "Humanities and social science.

[12] Gyimah, S. O. (2002) "Ethnicity and infant mortality in SubSaharan Africa: The case of Ghana." Population Studies Centre, University of Western Ontario, Canada. http://www.ssc.uwo.ca/sociology/popstudis/dp/dp02-10.pdf (accessed 15/02/2012).

[13] Hessol, D. C. \& Gribble, J. N. (2005). Effects of Health Programmes on Child Mortality in Sub-Saharan African. Washington: National Academy Press.

[14] Hill, K., G Bicego and M. Mahy, (2001) "childhood Mortality in Kenya: An examination of Trends and Determinants in the late 1980s to mid 1990s". http://www.jhsph.edu/popcenter/publicationd/pdf/WPO-01. pdf (accessed 18/02/2012).

[15] Hobcraft, J. (1993) "Women's education, child welfare and child survival: a review of the evidence". Health Transition Review: 3(2): 159-173.

[16] Hobcraft, J. N., J. W. Mc Donald and S. O. Rutstein. (1985) "Demographic Determinants of Infant Early Child Mortality: A comparative Analysis". Population studies; 39: 363.

[17] Jansen, Paul K.; Nafula, Nancy; Manda, Damiano Kulundu; Mwabu, Germano; and Kimenyi, Mwangi S. 2002. "A Situational Analysis of Poverty in Kenya". KIPPRA working Paper No. 6, Nairobi: KIPPRA.

[18] Joshua K. and Jeroen K. Van Ginneken (2009), determinants of infant and child mortality in Zimbabwe, vol21/13 max planck institute for demographic research rostock, Germany. Page 367-384.

[19] Kenya National Bureau of Statistics (2011). Kenya Demographic and Health Survey.

[20] Kramer (1987). Gender differentials in child mortality: A review of the evidence. In Monica Das Gupta, Lincoln Chen, and T. N. Krishnan, eds. Women's health in India: Risk and vulnerability. Bombay: Oxford University Press.

[21] Lovel, B. R. and J. A. C. Sterne. (1989): "Logistic regression: comparing to or more exposure groups". Essential Medical Statistics, Second Edition. Blackwell Publishing Company, United Kingdom.

[22] Manda, S. O. M. (1999). Birth intervals, breastfeeding and determinants of childhood mortality in Malawi. Social Science and Medicine 48 (3): 301-312. doi: 1016/S0277-9536 (98) 00359-1. 
[23] Madise, N. J. (2003). Infant mortality in Zambia: Socioeconomic and demographic correlates. Social biology. Accessed from www.findarticles.com/p/articles/miqa3998, on $18 / 02 / 2012$.

[24] Madise, N. J., Z.Matthews and B. Margetts (1999). Heterogeneity in child nutritional status between households: a comparison of six sub-Saharan African countries. Popuration Studies 53:331-343.

[25] Mc Elroy, P. D., F. O. Ter Kuile, A. W. Hightower, W. A. Hawlley, P. A. Phillips-Howard, A A. J. Oloo, A. A. Lal and B. L. Nahlen. (2001). All course mortality among young children in western Kenya". American Journal of tropical Medicine and Hygiene.64:18-27.

[26] Mosley, W. H. and Chen, L. C. (1984). An analytical framework for the study of child survival in developing countries. Population and development Review 10:25-45.

[27] Mturi, A. J. and S. L. Curtis. (1995): The determinants of infant and child mortality in Tanzania". Health Policy Plan; 10:384-394.

[28] Mutunga, C. J. (2004). "Environmental Determinants of Child Mortality in Kenya". Kenya Institute for Public Policy Research and Analysis (KIPPRA), Nairobi Kenya. (accessed 21/02/2012).
[29] Park, K. (2005). "Preventive Medicine in Obstetrics, Pediatrics and Geriatrics", PARK'S textbook of preventive and social medicine, (18th edition) India: BHANOT (2005); pp414-422.

[30] SPSS (2008). SPSS, Release 20.0. Advanced Statistical Procedures Companion. Chicago: SPSS Inc.

[31] Steve K. Sudhanshu H. and Shu W. N. (2010) "Child Mortality in Eastern and Southern Africa" Volume 49, pp. 835 .

[32] Troe, M. (2006). Infant Mortality and its underlying Determinants in Rural Malawi (Dissertation). University of Tampere Medical School.

[33] Tulasidhar, V. B. (1993) "Maternal education female labor force participation and child mortality evidence from the Indian census". Health Transition Review; 3(2): 177-190.

[34] UNICEF. (2006). Levels and Trends in Child Mortality, Report 2006, New York: UNICEF.

[35] UNITED NATIONS (2007). child mortality in developing countries socio-economic differentials. Trends and implications. New York.

[36] Zerai, A. (1996). Preventive health strategies and infant survival in Zimbambwe. African Population studies 11 (1): 29-62. 